\title{
ÍNDICE DE QUALIDADE DE DICKSON E CARACTERÍSTICA MORFOLÓGICA DE MUDAS DE PEPINO, PRODUZIDAS EM DIFERENTES SUBSTRATOS ALTERNATIVOS
}

\author{
Maria do Bom Conselho Lacerda Medeiros ${ }^{1}$; Hanna Ibiapina de Jesus ${ }^{2}$; Núbia de Fátima Alves Santos ${ }^{3}$; \\ Márcio Roberto da Silva Melo4; Vitor Quintela de Souza ${ }^{5}$; Luciana da Silva Borges ; \\ Guerreiro ${ }^{7}$; Luís de Souza Freitas ${ }^{8}$. \\ ${ }^{1}$ Universidade Federal Rural de Pernambuco, Serra Talhada, Pernambuco, Brasil, \\ melyagronomia@hotmail.com \\ 2 Universidade Federal Rural da Amazônia, Paragominas, Pará, Brasil, hanna_ij@hotmail.com \\ 3Universidade Federal Rural da Amazônia, Paragominas, Pará, Brasil, nubia.santos@ufra.edu.br \\ ^universidade Federal Rural da Amazônia, Paragominas, Pará, Brasil, marcio.melo@ufra.edu.br \\ 5Universidade Federal Rural da Amazônia, Paragominas, Pará, Brasil, luciana.borges@ufra.edu.br \\ 6Universidade Federal Rural da Amazônia, Paragominas, Pará, Brasil, luis.freitas@ufra.edu.br \\ 7Universidade Federal Rural da Amazônia, Paragominas, Pará, Brasil, quintelav@gmail.com \\ ¿Universidade Federal da Paraíba, Pombal, Paraíba, maracguerrero@hotmail.com
}

RESUMO: O pepino (Cucumis sativus L.) é uma hortaliça fruto de hábito indeterminado e anual, sendo muito apreciada em todas as regiões brasileiras. A grande versatilidade oferecida por esta cultura permite sua exploração em diferentes condições edafoclimáticas e níveis tecnológicos, garantindo sua importância econômica e social dentro do agronegócio de hortaliças no Brasil. O objetivo do estudo foi avaliar a qualidade de Dickson e as características morfológicas das mudas de pepino, produzidas em diferentes substratos obtido através do aproveitamento de recursos locais da região de Paragominas- Pará. O experimento foi conduzido na Universidade Federal Rural da Amazônia, campus de Paragominas, na área experimental de Horticultura, durante o período de fevereiro a março de 2016, utilizou-se o delineamento estatístico inteiramente casualizados, com quatro tratamentos e cinco repetiç̃̃es. Os tratamentos foram quatro substratos: resíduo de soja; palha de arroz; substrato comercial, e mistura. Foram avaliadas as seguintes características, altura, massa fresca, massa seca, massa fresca da raiz, massa seca da raiz, diâmetro, número de folhas e Índice de Qualidade de Dickson. Todos os dados foram analisados estatisticamente através do programa SISVAR, com teste $\mathrm{F}$ ao nível de $5 \%$ de probabilidade e as médias comparadas pelo teste de Tukey. Mediante aos resultados para os quatro tratamentos propostos utilizados para a produção de mudas de pepino, foi possível constatar que o substrato mistura favoreceu o crescimento das mudas em comparação aos demais tratamentos, se sobressaindo também para os resultados obtidos para Índice de Qualidade de Dickson.

PALAVRAS-CHAVE: Crescimento, Hortaliça, Palha de arroz, Resíduo de soja. 


\title{
DICKSON QUALITY INDEX AND MORPHOLOGICAL CHARACTERISTIC OF CUCUMBER SEEDLINGS, PRODUCED ON DIFFERENT ALTERNATIVE SUBSTRATES
}

\begin{abstract}
Cucumber (Cucumis sativus L.) is a fruit vegetable of indeterminate habit and annual, being very appreciated in all Brazilian regions. The great versatility offered by this culture allows its exploitation in different edaphoclimatic conditions and technological levels, guaranteeing its economic and social importance within the agribusiness of vegetables in Brazil. The objective of the study was to evaluate the quality of Dickson and the morphological characteristics of cucumber seedlings, produced in different substrates obtained using local resources in the ParagominasPará region. The experiment was conducted at the Federal Rural University of Amazônia, campus of Paragominas, in the experimental area of Horticulture, during the period from February to March of 2016, the statistical design was completely randomized, with four treatments and five replications. The treatments were four substrates: soybean residue; rice straw; commercial substrate, and blend. The following characteristics were evaluated: height, fresh mass, dry mass, fresh root mass, root dry mass, diameter, number of leaves and Dickson Quality Score. All data were analyzed statistically through the SISVAR program, with $F$ test at the 5\% probability level and the means compared by the Tukey test. By means of the results for the four proposed treatments used to produce cucumber seedlings, it was possible to verify that the substrate mixture favored the growth of the seedlings in comparison to the other treatments, also standing out for the results obtained for Dickson Quality Index.
\end{abstract}

KEYWORDS: Growth, Rice straw, Soybean residue, Vegetables.

\section{ÍNDICE DE CALIDAD DE DICKSON Y CARACTERÍSTICA MORFOLÓGICA DE LOS PLANTONES DE PEPINO, PRODUCIDOS EN DIFERENTES SUSTRATOS ALTERNATIVOS}

RESUMEN: El pepino (Cucumis sativus L.) es una hortaliza fruto de hábito indeterminado y anual, siendo muy apreciada en todas las regiones brasileñas. La gran versatilidad ofrecida por esta cultura permite su explotación en diferentes condiciones edafoclimáticas y niveles tecnológicos, garantizando su importancia económica y social dentro del agronegocio de hortalizas en Brasil. El objetivo del estudio fue evaluar la calidad de Dickson y las características morfológicas de las mudas de pepino, producidas en diferentes sustratos obtenidos a través del aprovechamiento de recursos locales de la región de Paragominas-Pará. El 
experimento fue conducido en la Universidad Federal Rural de la Amazonia, Paragominas, en el área experimental de Horticultura, durante el período de febrero a marzo de 2016, se utilizó el delineamiento estadístico completamente casualizado, con cuatro tratamientos y cinco repeticiones. Los tratamientos fueron cuatro sustratos: residuo de soja; paja de arroz; sustrato comercial, y mezcla. Se evaluaron las siguientes características, altura, masa fresca, masa seca, masa fresca de la raíz, masa seca de la raíz, diámetro, número de hojas e índice de calidad de Dickson. Todos los datos fueron analizados estadísticamente a través del programa SISVAR, con prueba $\mathrm{F}$ al nivel del 5\% de probabilidad y las medias comparadas por el test de Tukey. Por medio de los resultados para los cuatro tratamientos propuestos utilizados para la producción de mudas de pepino, fue posible constatar que el sustrato mezcla favoreció el crecimiento de las mudas en comparación a los demás tratamientos, sobresaliendo también para los resultados obtenidos para el índice de calidad de Dickson.

PALABRAS CLAVE: Crecimiento, Hortalizas, Paja de arroz, Residuo de soja.

O pepino (Cucumis sativus L.) é uma hortaliça fruto de hábito indeterminado e anual, sendo muito apreciada em todas as regiões brasileiras, (EMBRAPA, 2012). Pertence à família Cucurbitaceae, sendo uma hortaliça de importância socioeconômica no Brasil, (MARTINS, 2011). Além do valor econômico e alimentar, o cultivo de cucurbitáceas também tem grande importância social e demanda grande quantidade de mão-de-obra, desde o cultivo até a comercialização, (SANTI et al., 2013).

As principais características da planta são o hábito de crescimento indeterminado, rasteiro ou trepador com o auxílio de tutores, e ramos que apresentam gavinhas e hastes longas. Apresenta alta adaptabilidade a clima quente, com cultivo em temperaturas acima de $20^{\circ}$ C, motivo pelo qual é uma das espécies mais cultivadas em ambiente protegido, (SILVA et al., 2014; SEDIYAMA et al., 2014; GARCIA et al., 2016).

A grande versatilidade oferecida pela cultura do pepino, permite sua exploração em diferentes condições edafoclimáticas, estruturas fundiárias e níveis tecnológicos, assim garantindo sua importância econômica e social dentro do agronegócio de hortaliças no 
Brasil, (EMBRAPA, 2012). O Brasil apresenta condições climáticas necessárias para a produção dessa hortaliça exótica tropical, (ANTUNES et al., 2014).

Os substratos são considerados material sólido, natural, residual, mineral ou orgânico, que permite a fixação do sistema radicular, fornecendo nutrientes e suprindo as exigências de água e oxigênio necessárias ao desenvolvimento inicial da planta, (SMIRDELE et al., 2001; BOLDT, 2014). Logo, o substrato exerce influência marcante na produção de mudas, sendo essencial que os materiais utilizados reúnam diversas características que sejam favoráveis ao desenvolvimento vegetal, (CALDEIRA et al., 2008). O substrato deve apresentar boa textura, aeração, drenagem, e capacidade regular para a retenção de água disponível para as plantas, (FILGUEIRA, 2008).

Na produção de mudas as principais características específicas a serem controladas é a obtenção de plantas com maior uniformidade de crescimento da parte aérea e do sistema radicular, promovendo maior resistência às condições adversas do campo, (CORREIA et al., 2013). Alguns fatores estão diretamente ligados a qualidade das mudas, como, qualidade da semente, tipo de recipiente, substratos utilizados, adubação e práticas de manejo das mudas em geral, (CALDEIRA et al., 2008)

A utilização de materiais orgânicos como substratos alternativos para a produção de mudas está diretamente relacionada com a disponibilidade de materiais regionais, que podem ser obtidos facilmente e são mais acessíveis economicamente, (SANTOS et al., 2015). Leite et al. (2014), afirmaram ser de grande importância o conhecimento das características físicas e químicas presentes nesses materiais, de forma que seja possível a elaboração de um substrato que atenda as exigências da cultura implantada e auxilie na produção de mudas vigorosas e com bom desempenho no campo.

Para definir um padrão de mudas consideradas ideais para o plantio, são 
utilizados testes que buscam determinar ao máximo a sua qualidade. Constituídos por parâmetros baseados em aspectos morfológicos ou fisiológicos da planta, (GOMES et al., 2002). Segundo Rudek et al., (2013) o IQD tem sido empregado com êxito para avaliar o comportamento de mudas de várias espécies em campo.

De acordo com Fonseca et al. (2002) e Azevedo et al. (2010), o índice de qualidade de Dickson é um bom indicador da qualidade das mudas. $\mathrm{O}$ seu cálculo considera o equilíbrio da distribuição da biomassa na planta, ponderando os resultados de vários parâmetros importantes empregados para avaliação da qualidade da muda, sua fórmula determina o IQD inclui os parâmetros morfológicos de altura, diâmetro e biomassas. Diante do exposto, o objetivo do estudo foi avaliar a qualidade de Dickson e as características morfológicas das mudas de pepino, produzidas em diferentes substratos obtido através do aproveitamento de recursos locais da região de Paragominas- Pará.
O experimento foi conduzido na Universidade Federal Rural da Amazônia, campus de Paragominas, na área experimental de Horticultura. O município de Paragominas está localizado entre as coordenadas geográficas $02^{\circ} \quad 5^{\prime} \quad 24^{\prime \prime} S$ e $47^{\circ}$ 34'36"W. Os solos da área de estudo são do tipo Latossolo Amarelo muito argiloso, (EMBRAPA, 1999). O clima da região é do tipo Awi, segundo a classificação de Köppen, isto é, tropical chuvoso com estação seca bem definida, com temperatura média anual de $26,5^{\circ} \mathrm{C}$. A umidade relativa do ar varia de $70 \%$ a 90\%, (RODRIGUES et al., 2002).

O experimento foi conduzido entre fevereiro e março de 2016, em viveiro, com dimensões 4x12m com pé direito de 2,30 m, coberto com sombrite $70 \%$. As bandejas foram colocadas em bancadas de madeira, com altura de 70 cm, e 60x220 cm. O delineamento estatístico foi inteiramente casualizados, com quatro tratamentos e cinco repetições. Os tratamentos foram quatro substratos: resíduo de soja; palha 
de arroz; substrato comercial, e mistura: resíduo de soja (40\%) + palha de arroz (30\%)+ substrato comercial (30\%). Cada tratamento foi composto de 32 células da sementeira, permanecendo no final uma planta por célula, sendo cada repetição a média de 128 plantas. As características químicas da palha do arroz serão representadas na Tabela 1.

Tabela 1. Análise química da palha de arroz.

\begin{tabular}{|c|c|c|c|c|c|c|c|c|c|}
\hline P Total & $F$ & $\mathrm{Ca}$ & $\mathrm{Mg}$ & $\mathrm{Fe}$ & $\mathrm{Al}$ & $\mathrm{Cu}$ & $\mathrm{Zn}$ & $\mathrm{Mn}$ & $\mathrm{Na}$ \\
\hline \multicolumn{6}{|c|}{ - } & \multicolumn{4}{|c|}{ 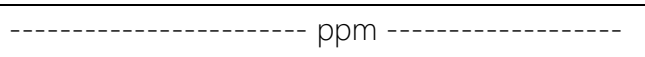 } \\
\hline 0,4 & 0,08 & 0,04 & 0,05 & 2,67 & 5,22 & 0 & 58,06 & 99,38 & 273,81 \\
\hline$B$ & M.O. & Umidade & $S$ & N Total & Cinzas & $\mathrm{pH}(\mathrm{CaCl} 2)$ & Mo & Cobalto & Densidade \\
\hline \multicolumn{7}{|c|}{ - } & \multicolumn{2}{|c|}{----- ppm ----- } & $\mathrm{g} / \mathrm{cm}^{3}$ \\
\hline 0,01 & 57,34 & 14,73 & 0 & 0,47 & 42,66 & 4,8 & 8,67 & 0 & 0,2 \\
\hline
\end{tabular}

Fonte: IBRA Laboratório.

A palha de arroz, foi obtida em uma empresa local, onde foi curtido por um ano e meio. O resíduo de soja, foi obtido em uma empresa do setor de grãos, curtido na área experimental de horticultura da UFRA campus Paragominas por um ano e meio, e peneirado com peneira do tipo pedreiro em aço com bordas de madeira e 60 cm de diâmetro, sua composição química está representada na Tabela 2. O substrato comercial, constituído de casca de pinus, turfa, nitrato de amônio, nitrato de potássio, superfosfato simples e produtos formulados por terceiros, de natureza sólida (sem especificação granulométrica), umidade $60 \% \mathrm{p} / \mathrm{p}$, capacidade de retenção de água de 130\% p/p, densidade (base seca) 180 $\mathrm{kg} / \mathrm{m}^{3}$, densidade (base úmida) 500 $\mathrm{kg} / \mathrm{m}^{3}, \mathrm{pH}$ de 5,8 e CE de 1,5 (ms/cm).

Foi utilizada a cultivar de pepino Cucumis sativus L., var. folha larga, com 
pureza de 100\% e índice de germinação de 95\%, segundo informações descritas pelo fabricante. A semeadura ocorreu em bandejas de polietileno expandido com 128 células colocando três sementes em cada célula a uma profundidade de $1 \mathrm{~cm}$. O início da germinação ocorreu ao quarto dia após a semeadura (DAS), e aos onze dias, foram desbastadas, permanecendo uma planta por célula. Decorridos 20 dias após a semeadura, foram avaliadas seguintes características: altura da parte aérea $(\mathrm{mm})$, número de folhas por planta, peso da massa seca e fresca da parte aérea e das raízes de quinze plântulas (g).

As alturas das plântulas foram determinadas medindo do colo até o ápice da parte aérea com auxílio de uma régua graduada. Levadas para o laboratório, as raízes foram separadas da parte aérea com auxílio de tesoura de poda e lavadas em água corrente. Em seguida, determinou-se o diâmetro do colo utilizando um paquímetro digital de precisão $0,01 \mathrm{~mm}$. A parte aérea e as raízes foram pesadas em balança analítica de precisão - (0,01 g) para determinar massa fresca e depois, acondicionadas em sacos de papel separados e etiquetados. Após a determinação da massa fresca e diâmetro, o material fresco foi transferido para secar em estufa com circulação forçada de ar a uma temperatura de $65^{\circ} \mathrm{C}$ por 72 horas, até atingir massas constantes para se determinar a massa seca.

Índice de Qualidade de Dickson (IQD): Para este índice foi utilizada a metodologia de Dickson et al. (1960) considerando os indicadores de massa seca da parte aérea, das raízes e de massa seca total, altura e diâmetro do colo das mudas.

$$
I Q D=\frac{\text { PMSTotal }}{\left(\frac{A P}{D C}\right)+\left(\frac{P M S P A}{P M S R}\right)}
$$

Onde: IQD) Índice de desenvolvimento de Dickson; MST) Massa seca total (g); H) Altura (cm); DC) Diâmetro do colo (cm); PMSPA) Peso da matéria seca da parte aérea (g); PMSRA) peso da matéria seca da raiz (g); RPAR) Relação da matéria seca da parte aérea com a matéria seca de raízes; RAD) Relação da altura parte aérea com o diâmetro do coleto. 
Tabela 2. Análise química do resíduo de soja, adquiridos nas empresas de grãos em Paragominas - PA, 2016.

\begin{tabular}{|c|c|c|c|c|c|c|c|c|c|}
\hline P Total & $F$ & $\mathrm{Ca}$ & $\mathrm{Mg}$ & $F$ & Al & $\mathrm{Cu}$ & $\mathrm{Zn}$ & $\mathrm{Mg}$ & $\mathrm{Na}$ \\
\hline ------ & ----- & - & --- \% - & - & -------- & $-\cdots$ & --- & $--p p m--$ & $-\cdots$ \\
\hline 1,12 & 1,05 & 0,89 & 0,36 & 1,28 & 4,12 & 5,57 & 90,29 & 75,31 & 287,36 \\
\hline B & M.O. & Umidade & Enxofre & N Total & Cinzas & $\mathrm{pH}$ & Mo & Cobalto & Densidade \\
\hline \multicolumn{7}{|c|}{ 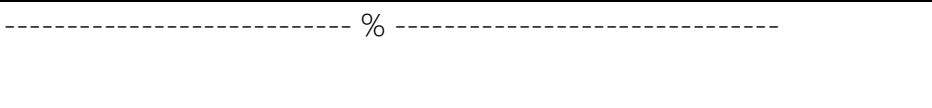 } & \multicolumn{2}{|c|}{ 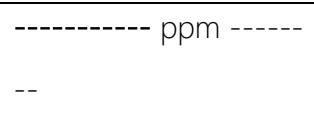 } & $\mathrm{g} / \mathrm{cm}^{3}$ \\
\hline 0,01 & 63,65 & 10,33 & 0 & 2,16 & 36,35 & 7,7 & 9,75 & 2,22 & 0,41 \\
\hline
\end{tabular}

Fonte: IBRA Laboratório

Todos os dados obtidos foram analisados estatisticamente através da análise de variância, com teste $F$ ao nível de 5\% de probabilidade e as médias comparadas pelo teste de Tukey, utilizando o programa SISVAR, (FERREIRA, 2000).

Para a característica de altura de mudas verifica-se na Tabela 3, que a mistura de resíduo de soja (40\%) + palha de arroz (30\%) + substrato comercial (30\%), foi superior ao substrato palha de arroz. ARAGÃO et al. (2011), trabalhando com mudas de melão, obteve altura de 10,39 cm com o substrato Plantmax $\mathrm{HT}^{\odot}$. Freitas et al., (2013) trabalhando com mudas de alface observaram que os substratos alternativos apresentaram maior desenvolvimento na altura de plantas, em relação ao substrato comercial Plantmax ${ }^{\circledR}$. Estudo conduzidos por Coêlho et al., (2013), avaliando mudas de pimentão em diferentes substratos obtiveram altura de 5,05 a 8,03 cm, resultados abaixo dos obtidos nesse estudo.

Para a característica de massa fresca, constatou-se que o substrato mistura foi superior ao substrato comercial, apresentando massa de 1,84 g, enquanto que os demais substratos avaliados não diferiram estatisticamente. 
Tabela 3. Indicadores morfológicos em mudas de pepino, cultivadas em diferentes substratos alternativos. Paragominas - PA, 2016.

\begin{tabular}{|c|c|c|c|c|c|c|c|}
\hline Tratamento & $\begin{array}{l}\text { Altura } \\
(\mathrm{cm})\end{array}$ & $\begin{array}{c}\text { Massa } \\
\text { fresca } \\
\text { (g) }\end{array}$ & $\begin{array}{c}\text { Massa } \\
\text { seca }\end{array}$ & $\begin{array}{c}\text { Massa } \\
\text { fresca } \\
\text { raiz }\end{array}$ & $\begin{array}{c}\text { Massa } \\
\text { seca raiz }\end{array}$ & Diâmetro & $\begin{array}{l}\text { Número } \\
\text { de folhas }\end{array}$ \\
\hline Palha & $11,98 \mathrm{~b}$ & $1,38 \mathrm{ab}$ & $0,08 \mathrm{~b}$ & $0,14 b$ & $0,01 \mathrm{a}$ & $3,01 a b$ & $2,12 \mathrm{a}$ \\
\hline Resíduo/soja & $13,53 \mathrm{ba}$ & $1,56 a b$ & 0,08 bc & $0,20 a$ & $0,02 \mathrm{a}$ & $3,05 \mathrm{ab}$ & $1,96 a b$ \\
\hline Comercial & $12,38 \mathrm{ba}$ & $1,30 \mathrm{~b}$ & $0,07 c$ & $0,12 b$ & $0,01 \mathrm{a}$ & $2,78 b$ & $1,71 b$ \\
\hline Mistura & 14,26 a & $1,84 \mathrm{a}$ & $0,11 \mathrm{a}$ & $0,13 b$ & $0,01 \mathrm{a}$ & $3,35 a$ & $2,01 \mathrm{ab}$ \\
\hline Cv(\%) & 8,90 & 17,89 & 11,28 & 20,92 & 17,64 & 7,88 & 11,00 \\
\hline
\end{tabular}

Onde: Letras minúsculas comparam médias das variáveis. Médias seguidas das mesmas letras não diferem estatisticamente entre si pelo teste de Tukey à $5 \%$ de probabilidade.

Analisando os resultados de massa seca da parte aérea constatou-se um incremento para esta variável em função do substrato mistura, apresentando significância aos demais substratos, onde foi possível observar a menor média no tratamento à base do substrato comercial. Possivelmente, uma menor disponibilidade de nutrientes no substrato comercial e a lixiviação por irrigação limitaram o acúmulo de massa seca nas mudas, (BRANDÃO, 2000; COSTA et al., 2013). Provavelmente, a superioridade do resultado obtido no tratamento mistura pode ser atribuída ao teor de matéria orgânica e nutrientes no material, favorecidos pela mistura dos materiais RS+PA+SC. A utilização de matéria orgânica, além de disponibilizar nutrientes à plântula, melhora as condições físicas do substrato, (RODRIGUES et al., 2010).

O maior teor de massa fresca das raízes foi obtido no tratamento à base de resíduo de soja, diferindo estatisticamente aos demais tratamentos palha de arroz, mistura e substrato comercial. Para à massa seca da raiz, é possível constatar que não houve efeito significativo entre os diferentes substratos avaliados. Barros Júnior et al., (2008), obtiveram resultados diferentes dos encontrados 
nesse trabalho com relação a massa seca das raízes, avaliando a produção de mudas de pimentão, observaram superioridade significativa dos compostos orgânicos sobre o substrato comercial Plantmax ${ }^{\circledR}$.

Enquanto que ao número de folhas, a maior média foi obtida pelo substrato palha de arroz, seguindo com valores similares para o substrato comercial, e não diferiu estatisticamente das médias dos substratos mistura e resíduo de soja. Tessaro et al. (2013), afirma que o número de folhas é um dos parâmetros mais importantes a serem avaliados no cultivo de mudas, pois um bom desenvolvimento da porção aérea permite à planta uma maior capacidade de fotossíntese. Coêlho et al. (2013), obtiveram diferenças significativas para as características de altura da parte aérea, comprimento da raiz e número de folhas em mudas de pimentão cultivadas em diferentes substratos.

As plântulas cultivadas no substrato mistura apresentaram o maior diâmetro, seguindo com valores inferiores para o substrato comercial, em relação ao substrato palha de arroz e resíduo de soja não houve efeito significativo. Santos et al. (2015), avaliando a qualidade de mudas de tomate, também verificaram diferenças significativas nas médias de diâmetro do colo em função do substrato, com incrementos para essa variável pelo uso de materiais alternativos, pois o diâmetro do colo é um bom indicador da qualidade da muda, quanto o valor, maiores as chances de sobrevivência e crescimento da muda após o transplantio. Tais resultados corroboram com Leal et al. (2007) e Oliveira et al. (2013), avaliando a produção de mudas de tomate em função do substrato, observaram incrementos no desenvolvimento das plântulas, utilizando diferentes misturas com compostos orgânicos em comparação ao substrato comercial.

Na Tabela 4 é possível constatar os resultados para as relações de RAD, 
RPAR e IQD em mudas de pepino. Houve diferenças significativas entre os parâmetros avaliados para RPAR e IQD. Quanto aos valores obtidos para RAD, não ocorreu diferenças significativas entre os tratamentos, porém apresentou menor média para esta relação corresponde às plântulas produzidas no substrato palha de arroz que obtiveram menor crescimento em altura e, em contrapartida, um bom desenvolvimento do diâmetro do colo; enquanto a maior média foi obtida a partir do substrato resíduo de soja, em função do maior incremento de altura no tratamento.

Tabela 4. Índice de qualidade em mudas de pepino, produzidas em diferentes substratos alternativos. Paragominas-PA, 2016.

\begin{tabular}{llcc}
\hline Tratamento & RAD & RPAR & IQD \\
\hline Palha de arroz & $4,02 \mathrm{a}$ & $7,87 \mathrm{~b}$ & $7,83 \mathrm{~b}$ \\
Resíduo soja & $4,47 \mathrm{a}$ & $6,31 \mathrm{c}$ & $6,34 \mathrm{~d}$ \\
Mistura (PA+RS+C) & $4,41 \mathrm{a}$ & $10,88 \mathrm{a}$ & $11,11 \mathrm{a}$ \\
Comercial & $4,45 \mathrm{a}$ & $6,51 \mathrm{c}$ & $7,13 \mathrm{c}$ \\
\hline CV (\%) & 6,29 & 5,22 & 4,41 \\
\hline
\end{tabular}

Letras minúsculas comparam médias dos substratos. Médias seguidas das mesmas letras não diferem estatisticamente entre si pelo teste de Tukey à $5 \%$ de probabilidade.

A menor média de IQD observado na Tabela 4, pode ser verificada no tratamento contendo resíduo de soja, seguida pelo tratamento com substrato comercial. Em contraste, é possível observar que o tratamento com o substrato mistura se sobressaiu em relação aos demais, com uma média significativamente superior de
IQD. Tais resultados corroboram com Barros Júnior et al., (2008), trabalhando com substratos a base de compostos orgânicos, notaram que as mudas de pimentão apresentaram índices de desenvolvimento de Dickson superiores quando comparadas com 0 substrato comercial Plantmax ${ }^{\circledR}$. 
O maior valor de RPAR também foi encontrado neste tratamento utilizando o substrato mistura, seguindo com médias similares para o tratamento palha de arroz, enquanto que resíduo de soja e o substrato comercial apresentaram menores médias para este parâmetro avaliado.

Estes resultados provavelmente poderão ser justificados pelo crescimento proeminente da parte aérea das mudas produzidas no substrato mistura. Resultados semelhantes foram encontrados por Costa et al. (2015), pesquisando sobre a influência de diferentes substratos, observaram que a mistura de resíduos industriais e substrato comercial, proporcionou mudas de tomate cereja com maior qualidade, maior desenvolvimento das plantas, maior altura e diâmetro, fitomassas secas e IQD.

Constatou-se que o substrato mistura: resíduo de soja (40\%) + palha de arroz (30\%) + substrato comercial (30\%), favoreceu o crescimento das mudas de pepino, proporcionando maiores incrementos às mudas de acordo com as variáveis analisadas. Os resultados encontrados para Índice de Qualidade de Dickson foram satisfatórios, o que indica que o substrato mistura é um bom indicador da qualidade para a produção das mudas avaliadas nesse experimento.

\section{REFERÊNCIAS}

ARAGÃO, CARLOS A.; PIRES, MAYARA M. M. L.; BATISTA, PATRÍCIO F.; DANTAS, BÁRBARA F. Qualidade De Mudas De Melão Produzidas Em Diferentes Substratos. Revista Caatinga, vol. 24, n. 3, pág. 209-214. Mossoró, 2011.

ANTUNES, G.; FERREIRA, A. P. S.; PUIATTI, M.; CECON, P. R.; SILVA, G. C. Produtividade e qualidade de frutos de pepino africano em resposta à adubação nitrogenada. Revista Ceres, v. 61, n.1, p. 141-146, 2014.

ARAGÃO, C. A.; PIRES, M. M.; BATISTA, P. F.; DANTAS, B. F. Qualidade de mudas de melão produzidas em diferentes substratos.

Revista Caatinga, Mossoró, v. 24, n. 3, p. 209-214, 2011.

AZEVEDO, I. M. G.; ALENCAR, R. M.; BARBOSA, A. P.; ALMEIDA, N. O. Estudo do crescimento e qualidade de mudas de marupá (Simarouba amara 
Aubl) em viveiro. Acta Amazônica, v. 40, n. 1, p. 57-164, 2010.

BARROS JÚNIOR, A.P.; BEZERRA NETO, F.; SILVEIRA, L.M.; CÂMARA, M.J.T.; BARROS, N.M.S. Utilização de compostos orgânicos no crescimento de mudas de pimentão. Revista Caatinga, v. 21, p.126-130, 2008.

BOLDT, R. H. Formação de mudas e produção de rúcula em função dos substratos., Rio Branco, 2014, 40 f. Dissertação (Pós-Graduação em Agronomia) - Universidade Federal do Acre, Rio Branco, 2014.

BRANDÃO, F. D. Efeito de substratos comerciais no desenvolvimento de cultivares de alface na época de inverno, Uberlândia, 2000. 29 f. Monografia (Graduação em Agronomia) - Universidade Federal de Uberlândia, Uberlândia - MG, 2000.

CALDEIRA, M. V. W.; ROSA, G. N.; FENILLI, T. A. B.; HARBS, R. M. P. Composto orgânico na produção de mudas de aroeira-vermelha. Scientia Agraria, v. 9, n. 1, p. 27-33, 2008.

COÊLHO, J. L. S.; SILVA, R. M.; BAIMA, W. D. S.; GONÇALVES, H. R. O.; NETO, F. C. S.; AGUIAR, A. V. M. Diferentes substratos na produção de mudas de pimentão. ACSA - Agropecuária Científica no Semi-Árido, v.9, n.2, p.0104, abr-jun, 2013.

CORREIA, A.C.G. SANTANA, R.C.; OLIVEIRA, M.L.R.; TITON, M.; ATAÍDE, G.M.; LEITE, F.P. Volume de substrato e idade: influência no desempenho de mudas clonais de eucalipto após replantio. Cerne, Lavras, v. 19, n. 2, p. 185-191, 2013.

COSTA, E.; SANTO, T.L.E.; SILVA, A.P.; SILVA, L.E.; OLIVEIRA, L.C.; BENETT, C.G.S.; BENETT, K.S.S. Ambientes e substratos na formação de mudas e produção de frutos de cultivares de tomate cereja. Horticultura Brasileira, v. 33, n. 01, p. 110-118, 2015.

COSTA, L.A. M. COSTA, M.S.S.M.; PEREIRA, D.C.; BERNARDI, F.H.; MACCARI, S. Avaliação de substratos para a produção de mudas de tomate e pepino. Revista Ceres, v. 60, n. 5, p. 675, 2013.

DICKSON, A.; LEAF, A.; HOSNER, J.F. Quality appraisal of white spruce and white pine seedling stock in nurseries. The Forest Chronicle, West Mattawa, v. 36, p. 10-13, 1960.

EMBRAPA. Centro Nacional de Pesquisa de Solos. Sistema Brasileiro de Classificação de Solos. Brasília-DF, Embrapa Solos, 1999, 412p.

EMBRAPA. Recomendações técnicas para o controle de pragas do pepino. Circular técnica. p. 15, 2012.

FERREIRA, D. F. Programa Sisvar. exe: Sistema de análise de variância. Versão 3.04. Programa Sisvar. exe: sistema de análise de variância. Versão 3.04, 2000.

FILGUEIRA FAR. Manual de olericultura: Agrotecnologia moderna 
na produção e comercialização de hortaliças. Viçosa: UFV, 402p. 2008.

FONSÊCA, T. G. Produção de mudas de hortaliças em substratos de diferentes composições com adição de $\mathrm{CO}^{2}$ na água de irrigação. Piracicaba, 2001, 72 f. Dissertação (Mestrado em Agronomia) Universidade de São Paulo, Piracicaba, 2001.

FREITAS, G. A.; SILVA, R. R.; BARROS, H. B.; VAZ-DE-MELO, A.; ABRAHÃO, W. A. P. Produção de mudas de alface em função de diferentes combinações de substratos. Revista Ciência Agronomica, v. 44, p.159-166, 2013.

GARCIA, R. V.; COSTA, A. C. ; DELPRETE, S. I. ; SILVA, M. G. ; LIMA, W. L. Efeito da Borra de Café na formação de mudas de pepino (Cucumis sativus L.). Cadernos de Agroecologia, v. 11, n. 2, 2016.

GOMES, J. M.; COUTO, L.; LEITE, H.G.; XAVIER, A.; GARCIA, S.L.R. Parâmetros morfológicos na avaliação da qualidade de mudas de Eucalyptus grandis. Revista Árvore, v. 26, n. 6, p. 655-664, 2002.

LEAL M. A.; GUERRA, J. G. M; PEIXOTO, R. T.G. ALMEIDA, D. L. Utilização de compostos orgânicos como substratos na produção de mudas de hortaliças. Horticultura Brasileira, v. 25, n. 3, p. 392-395, 2007.

LEITE, R. C.; CARNEIRO, J.S.S.; FARIA, A.J.G.; FREITAS, G.A.; SANDI, F.; CERQUEIRA, F.B. Influência de substratos e recipientes no desenvolvimento de mudas de pepino. In: ENCONTRO DE CIÊNCIA DO SOLO DA AMAZÔNIA ORIENTAL, 1., 2014, Gurupi, TO. Anais... Trabalhos completos, Gurupi-TO: Sociedade Brasileira de Ciência do Solo, 2014, p. 140-150.

MARTINS, W. M. O.; MARTINS, W. J. O.; MARTINS, L. M. O. Produção agroecológica de mudas de pepino com substratos alternativos. Cadernos de Agroecologia, v. 6, n. 2, p. 1-5, 2011.

OLIVEIRA, J. R.; XAVIER, F. B.; DUARTE, N. F. Húmus de minhoca associado a composto orgânico para a produção de mudas de tomate. Revista Agrogeoambiental, v. 5, n. 2, p.79-86, 2013.

RODRIGUES, E. T.; LEAL, P. A. M.; COSTA, E.; PAULA, T. S.; GOMES, V. A. Produção de mudas de tomateiro em diferentes substratos e recipientes em ambiente protegido. Horticultura Brasileira, v. 28, n. 4, p. 483-488, 2010.

RODRIGUES, T. E. VALENTE, M.A.; GAMA, J.R.N.F.; OLIVEIRA JÚNIOR, R.C.; SANTOS, P.L.; SILVA, J.L. Zoneamento Agroecológico do município de Paragominas, Estado do Pará. Boletim Técnico Embrapa Amazônia Oriental. Belém: Embrapa, 2002, 64 p.

RUDEK, A.; GARCIA, F. A. O.; BANDEIRA, F. S. Avalição da qualidade de mudas de eucalipto pela mensuração da área foliar com o uso 
de imagens digitais. Enciclopédia Biosfera, Goiânia, v. 9, n. 17, p. 37753787, 2013.

SANTI, A.; SCARAMUZZA, W. L. M. P.; SOARES, D. M. J.; SCARAMUZZA, J. F.; DALLACORT, R.; KRAUSE, W.; TIEPPO, R. C. Desempenho e orientação do crescimento do pepino japonês em ambiente protegido. Horticultura Brasileira, v. 31, n. 4, p. 649-653, 2013.

SANTOS, A. C. M.; CARNEIRO, J.S.S.; FERREIRA JUNIOR, J.M.; SILVA, M.C.A.; SILVA, R.R. Produção de mudas de tomateiro cV. Drica sob substratos alternativos. Agropecuária Científica no Semiárido, v. 11, n. 4, p. 1-12, 2015.

SEDIYAMA, M. A. N.; NASCIMENTO, J.L.M.; LOPES, I.P.C.; LIMA, P.C.; VIDIGAL, S.M. Tipos de poda em pepino dos grupos aodai, japonês e caipira. Horticultura Brasileira, v. 32, n. 4, p. 491-496, 2014.

SILVA, E. F. SOUZA, E.G.F.; SANTOS, M.G.; ALVES, M.J.G.; BARROS JÚNIOR, A.P.; SILVEIRA, L.M.; SOUSA, T.P. Qualidade de mudas de pepino produzidas em substratos à base de esterco ovino. Revista Agropecuária Científica No Semiárido, v. 10, n. 3, p. 93-99, 2014.

SMIDERLE, O. J.; SALIBE, A.B.; HAYASHI, A.H.; MINAMI, K. Produção de mudas de alface, pepino e pimentão em substratos combinando areia, solo e plantmax ${ }^{\circledR}$. Horticultura Brasileira, Brasília, v. 19, n. 3, p. 253257, 2001.
TESSARO, D.; MATTER, J.M.; KUCZMAN, O.; FURTADO, L.F.; COSTA, L.A.M.; COSTA, M.S.S.M. Produção agroecológica de mudas e desenvolvimento a campo de couvechinesa. Ciência Rural, v. 43, n. 5, p. 831-837, 2013. 